\title{
Clinical and Molecular Characteristics of
} Neonatal Extended-Spectrum $\beta$-LactamaseProducing Gram-Negative Bacteremia: A 12Year Case-Control-Control Study of a Referral Center in Taiwan

\author{
Ming-Horng Tsai ${ }^{1,2,3 \odot}$, I-Ta Lee ${ }^{4 \odot}$, Shih-Ming $\mathrm{Chu}^{2,5,6}$, Reyin Lien ${ }^{2,5,6}$, Hsuan- \\ Rong Huang $^{2,5,6}$, Ming-Chou Chiang ${ }^{2,5,6}$, Ren-Huei $\mathrm{Fu}^{2,5,6}$, Jen-Fu Hsu ${ }^{2,5,6 *}$, Yhu- \\ Chering Huang ${ }^{5,6,7 *}$
}

1 Division of Neonatology and Pediatric Hematology/Oncology, Department of Pediatrics, Chang Gung Memorial Hospital, Yunlin, Taiwan, 2 Division of Pediatric Neonatology, Chang Gung Memorial Hospital, Taoyuan, Taiwan, 3 Chang Gung University of Science and Technology, Chiayi, Taiwan, 4 Department of Anatomy, College of Medicine, China Medical University, Taichung, Taiwan, 5 Department of Pediatrics, Chang Gung Memorial Hospital, Taoyuan, Taiwan, 6 College of Medicine, Chang Gung University, Taoyuan, Taiwan, 7 Division of Pediatric Infectious Disease; Chang Gung Memorial Hospital, Taoyuan, Taiwan

ه These authors contributed equally to this work.

* ychuang@adm.cgmh.org.tw (YCH); jeff0724@gmail.com (JFH)

\section{G openaccess}

Citation: Tsai M-H, Lee I-T, Chu S-M, Lien R, Huang $\mathrm{H}-\mathrm{R}$, Chiang M-C, et al. (2016) Clinical and Molecular Characteristics of Neonatal Extended-Spectrum $\beta$ Lactamase-Producing Gram-Negative Bacteremia: A 12-Year Case-Control-Control Study of a Referral Center in Taiwan. PLoS ONE 11(8): e0159744. doi:10.1371/journal.pone.0159744

Editor: Dongsheng Zhou, Beijing Institute of Microbiology and Epidemiology, CHINA

Received: November 14, 2015

Accepted: July 7, 2016

Published: August 9, 2016

Copyright: $\odot 2016$ Tsai et al. This is an open access article distributed under the terms of the Creative Commons Attribution License, which permits unrestricted use, distribution, and reproduction in any medium, provided the original author and source are credited.

Data Availability Statement: All relevant data are within the paper.

Funding: These authors have no support or funding to report.

Competing Interests: The authors have declared that no competing interests exist.

\section{Abstract}

Extended-spectrum $\beta$-lactamase (ESBL)-producing Gram-negative bacteremia (GNB) in the neonatal intensive care unit was characterized by comparison with two control groups: a susceptible control group and a general base population group over 2001 to 2012. The influence of ESBL production on mortality was studied in all study subjects and ESBL-GNB isolates were microbiologically characterized. We identified 77 episodes of ESBL-GNB (14.2\% of all neonatal late-onset GNB), which were caused by Klebsiella spp. (62.3\%), E. coli (20.8\%) and Enterobacter spp. (16.9\%). Most ESBL-GNB strains were genetically unrelated and the SHV-type ESBLs were the most prevalent (67\% of isolates). Comparison with both control groups disclosed previous usage of $3^{\text {rd }}$ generation cephalosporin (odds ratio [OR], 4.72; 95\% confidence interval [Cl], 2.03-10.97; $\mathrm{P}<0.001$ ), and underlying renal disease (OR, 4.07; 95\% Cl, 1.10-15.08; $\mathrm{P}=0.035)$ as independent risk factors for ESBL-GNB. Inadequate empiric antibiotics, a higher illness severity, higher rates of infectious complications and sepsis-attributable mortality were more frequently seen in neonates with ESBLGNB than those with non-ESBL GNB (20.8\% and $15.6 \%$ vs. $9.2 \%$ and $7.9 \%$, respectively; $P=0.008$ and 0.049 , respectively). Neonates with underlying secondary hypertension (OR, 7.22; 95\% Cl, 2.17-24.06) and infectious complications after bacteremia (OR, 6.66; 95\% $\mathrm{Cl}, 1.81-19.31$ ) were identified as independent risk factor for in-hospital mortality. ESBLGNB accounted for one-seventh of all neonatal gram-negative bacteremia, especially in neonates exposed to broad-spectrum cephalosporins. Neonates with ESBL-GNB 


\section{Introduction}

Gram-negative bacilli are the second common cause of bloodstream infection (BSI) in the neonatal intensive care unit (NICU) [1,2]. Extended-spectrum $\beta$-lactamase (ESBL)-producing Gram-negative bacilli are the leading cause of nosocomially acquired multidrug-resistant organisms [3,4] and have been responsible for an increasing number of NICU outbreaks [5-7]. Infections caused by $\beta$-lactamase-producing Enterobacteriaceae have serious implications on NICU infection control practices, and are often associated with a delay in effective antibiotics administration. Besides, treatment options for ESBL-producing Gram-negative bacteremia (ESBL-GNB) are often limited, since these microorganisms are often resistant to other antimicrobials such as aminoglycosides, trimethoprim/sulfamethoxazole, or quinolones [8].

Currently, most studies on ESBLs in the NICU focused on successful control or molecular epidemiology of single outbreak [6,7,9-11]. Some investigated risk factors for colonization, acquisition and infection, or emergence of antimicrobial resistance [11-16]. Little is known about the clinical features about ESBL-GNB in the NICU. Moreover, these studies were limited by a suboptimal control group selection, comparing case patients with and without ESBL-producing pathogens infections [13-15], small sample size [15-18], or analyzing all nosocomial infections instead of focusing on bacteremia $[5,13-15,18]$. We therefore conducted this study to assess the clinical features, risk factors, and molecular epidemiology of ESBL-GNB in the NICU using a case-control-control analysis, which was recommended by Kaye et al [19] to overcome the limitations aroused by usual matched case-control studies.

\section{Materials and Methods}

\section{Study setting, participants and study design}

This study was carried out in the NICU of Chang Gung Memorial Hospital (CGMH), which contains three units with a total capacity of 49-bed in tertiary-care level and 58-bed of special care nurseries in a university-affiliated teaching hospital in Taiwan. The annual admissions were around 1,700 infants, and two-fifths of them were critically ill or preterm infants requiring mechanical ventilation. All infants $<34$ to 35 weeks' completed gestation, with a birth weight $<2 \mathrm{~kg}$ or $>5 \mathrm{~kg}$, or with any clinical signs of respiratory distress or cardiovascular, gastrointestinal, or neurologic problems requiring surgical or intensive treatment were eligible to admission in our NICU. This study was approved by the institutional review board of Chang Gung Memorial Hospital, with a waiver of informed consent because all patient records/information were anonymized and de-identified prior to analysis.

From January 2001 to December 2012, all the episodes of ESBL-GNB BSI were included in this study. Because only E. coli, K. pneumonia, K. oxytoca, E. cloacae, and E. aerogenes were ever identified as the causative microorganisms of neonatal ESBL-GNB, all neonatal late-onset BSI episodes due to these five pathogens without producing ESBL during the same period constituted the control group A. The control group B was from all hospitalized neonates: three control patients per case patient were chosen from those who were admitted within half a month before or after the case patient in the same unit, and had a hospital stay longer than the age at onset of ESBL-GNB in case patients. Polymicrobial infection was included in the cases if one of the isolates was an ESBL-producing strain, and also included in the first control group if one of the isolates was a GNB. All episodes of late-onset BSI were considered as different 
independent events, and we considered a new episode of BSI when the same organism was identified after a 14-day course of appropriate antibiotic therapy or one or more negative blood culture, or if a different organism was identified from a subsequent culture 7 days after the first one.

\section{Definitions and variables}

Criteria from the Centers for Disease Control (CDC) and Prevention were applied to define neonatal bacteremia or BSI [20]. Late-onset BSI was defined as at least one positive blood culture obtained after 72 hours of life. Congenital infection and early-ones sepsis were defined as a definite infectious focus and septicemia that occurred within the first 72 hours of life [3]. All comorbidities of prematurity, including respiratory distress syndrome (RDS), intraventricular hemorrhage (IVH), bronchopulmonary dysplasia (BPD), and necrotizing enterocolitis (NEC) were based on the latest updated diagnostic criteria in the standard textbook of neonatology [21].

Shock was defined as a mean blood pressure $<$ lower limit according to gestational age that was unresponsive to fluid treatment or required vasoactive agents [22]. Empirical antibiotics were considered to be inappropriate if the treatment regimen did not include at least one antibiotic that was active in vitro against the infecting microorganisms within 24 hours of blood culture collection. Prior antibiotic therapy was defined as systemic antibiotic $>72$ hours in the preceding 30 days before bacteremia onset. The outcomes variables were the in-hospital mortality, and we also compared the sepsis-attributable mortality and infectious complications between ESBL-GNB and the control group A. Infectious complications were defined as a newly infectious focus or persistent organ dysfunction which occurred within one week and directly related to bacteremia, but not concurrently at onset of bacteremia. Sepsis attributable mortality was defined as neonates who expired within three days after onset of bacteremia, those who died of infectious complications or clinically progressive deterioration since onset of bacteremia.

\section{Data collection}

In addition to a prospectively collected database as previously described [23,24], medical records of all study subjects were reviewed to collect the following data: exposure to central venous catheter (CVC), total parenternal nutrition (TPN), antibiotic or other medication, use of mechanical ventilation, clinical courses of all episodes of bacteremia, and treatment outcomes. The illness severity was evaluated by neonatal therapeutic intervention scoring system (NTISS) [25], calculated at the most severe period during the whole BSI episode. In the case group and the control group A, categorical variables were identified at the onset of bacteremia and continuous variables were identified before the onset of bacteremia. For control group B, these variables were identified throughout the whole course of hospital stay.

\section{Microbiological Characterization}

All blood samplings were ordered by the attending physicians in the presence of clinical features compatible with systemic inflammatory response syndrome or when infection was suspected. Blood cultures were obtained through peripheral venous puncture (never through a CVC) and then performed using the BACTEC 9240 system. Antibiotic susceptibility patterns were determined according to methods recommended by the National Committee for Clinical Laboratory Standards Institute (CLSI) for disk diffusion method and categorical assignment was carried out using CLSI breakpoints [26]. ESBL production was screened and confirmed in all isolates with a profile suggestive of resistance by performing a double-disc synergy test 
according to CLSI guidelines [27]. The presence of $b l a_{\mathrm{SHV}}, b l a_{\mathrm{DHA}}, b l a_{\mathrm{CMY}}$ and $b l a_{\mathrm{CTX}-\mathrm{M}}$ genes was investigated by polymerase chain reaction (PCR) amplification, as previously described $[28,29]$. Molecular characterizations of ESBL-producing isolates were typed by infrequentrestriction-site PCR, and restriction patterns were analyzed by applying previously established criteria [29].

\section{Statistical analysis}

Categorical variables were compared by using the $\chi^{2}$ test or the Fisher exact test, and MannWhitney $U$ test and the $t$ test were used for comparison of continuous variables, depending on the distribution. To investigate the independent risk factors of ESBL-GNB and final mortality, conditional logistic regression was used to compute crude odds ratios (ORs) and $95 \%$ confidence intervals (CIs). Variables with a crude $P$ value of $<0.1$, those that were biologically sound, and those found in previous studies of ESBL-producing Enterobacteriaceae were introduced into the multivariate analysis performed by conditional logistic regression and then a stepwise backward process. All statistical analyses were performed using the SPSS version 15.0 (IBM SPSS Statistics, IBM Corporation, Armonk, NY).

\section{Results}

During the study period, 542 episodes of Gram-negative bacteremia (GNB) were identified in the NICU of CGMH. Of them, 77 (14.2\%) episodes occurred in a total of 71 patients were identified as ESBL-producing isolates, including E. coli (16 episodes), K. pneumonia (40 episodes), K. oxytoca (8 episodes), E. cloacae (12 episodes), and E. aerogenes (1 episode). All these ESBL-GNB were late-onset BSI. The control group A consisted of 316 episodes of GNB in 289 neonates, and the pathogens were E. coli (94 episodes), K. pneumonia (143 episodes), K. oxytoca (22 episodes), E. cloacae (37 episodes), and E. aerogenes (20 episodes). Only 8 patients had both ESBL and non-ESBL GNB during the study period. More than half (43/77, 55.8\%) of ESBL-GNB occurred before December 31, 2004 (first third of the study period) (Fig 1), and the incidence rate of ESBL-GNB decreased significantly after January 2005 when compared with that before the end of 2004 ( 1.34 vs. 3.33 per 10,000 neonate-hospital days, $\mathrm{p}<0.01$ ).

\section{Risk factors for neonatal bacteremia due to ESBL-producing microorganisms}

Demographics, perinatal history, most chronic comorbidities, and age at onset of BSI of the patients were comparable between the ESBL-GNB group and the non-ESBL GNB group. The duration of central venous catheter (CVC), ventilator and total parenternal nutrition (TPN) usages, and hospital stay were also comparable. Neonates with ESBL-GNB had a significantly higher rate of underlying congenital anomalies, gastrointestinal sequelae, renal disorders, and more frequent exposure to most antibiotics than those with non-ESBL GNB (Table 1). When compared with the control group $B$, which was made up of 231 uninfected patients, neonates with ESBL-GNB had higher rates of outborn, low Apgar score at 5 minutes, most chronic conditions, and more frequent exposure to antibiotics, CVCs placement, and TPN usage. Longer duration of CVC placement, ventilator and TPN uses, and hospital stay were also noted.

To identify independent risk factors for the occurrence of ESBL-GNB, the results of multivariate logistic regression are summarized in Table 2. Only two factors, antibiotic exposure to broad-spectrum cephalosporins and underlying renal disease were found independently associated with occurrence of ESBL-GNB when the case groups were compared to both the nonESBL GNB and uninfected controls. 


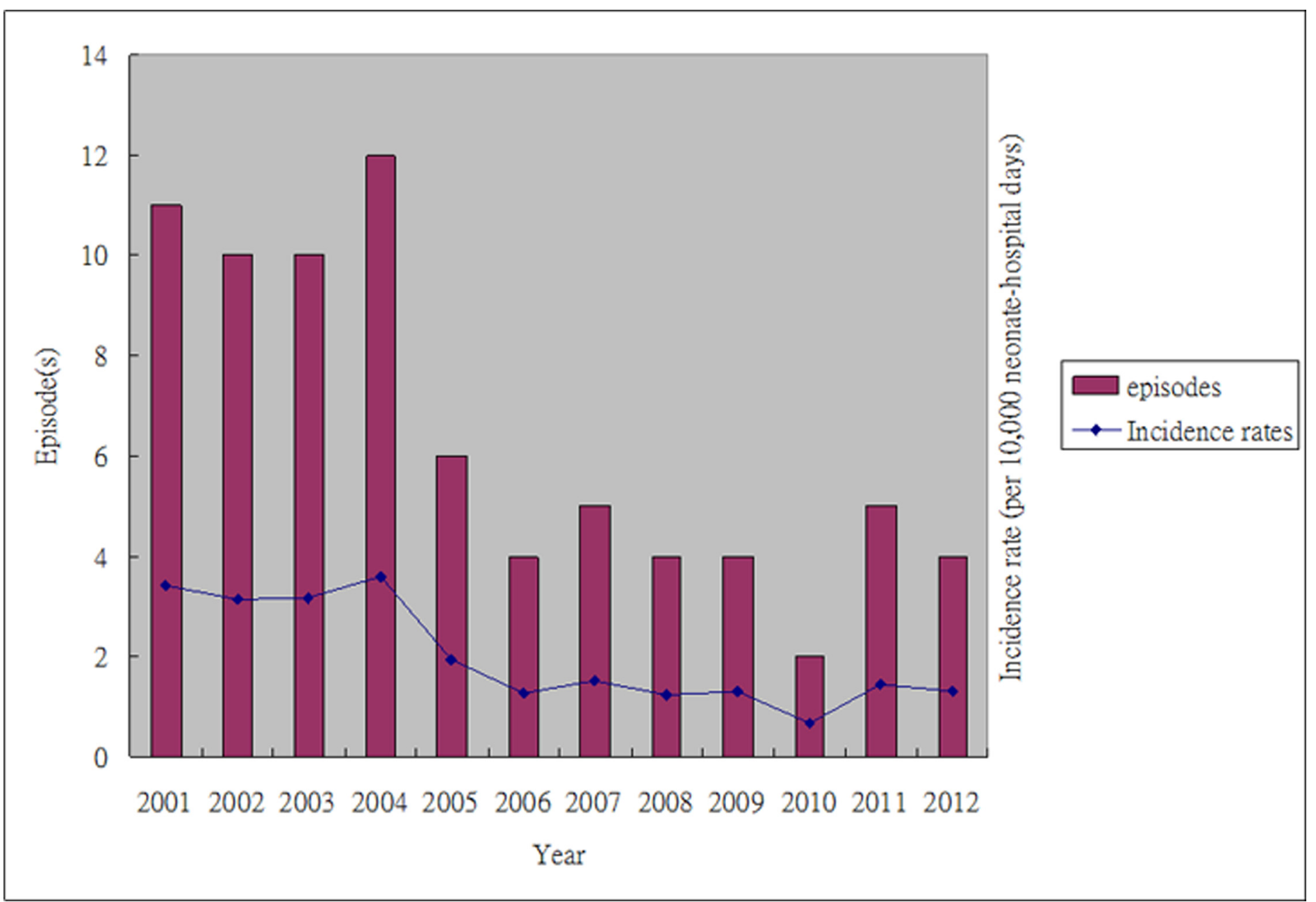

Fig 1. Bacteremia due to extended-spectrum $\beta$-lactamase (ESBL)-producing Enterobacteriaceae in the neonatal intensive care unit, 2001-2012, Episodes and clinical incidence rates per year.

doi:10.1371/journal.pone.0159744.g001

\section{Clinical features and prognosis}

The clinical and laboratorial manifestations seemed more severe in ESBL-GNB than non-ESBL GNB, including higher rate of disseminated intravascular coagulopathy, metabolic acidosis, thrombocytopenia, anemia, prolonged feeding intolerance and higher severity of illness (Table 3). Blood components transfusions and use of inotropic agents were therefore more often required in ESBL-GNB than non-ESBL GNB. All GNB were treated with empiric antibiotics, with no significant difference between groups regarding the antibiotic type administered. However, patients with ESBL-GNB more frequently received inadequate initial empirical antibiotic therapy compared with those with non-ESBL GNB (76.6\% vs. 9.5\%, $P<0.001)$, and time to adequate antibiotic therapy was also longer $(43.4 \pm 17.3$ hours vs. $3.7 \pm 10.4$ hours, $P<0.001)$. ESBL-GNB was associated with a poorer outcome than both non-ESBL GNB and the non-infected controls, including a higher rate of infectious complications (20.8\% vs. 9.2\%, $P=0.008)$ and sepsis-attributable mortality $(15.6 \%$ vs. $7.9 \%, \mathrm{p}=0.049)$.

The in-hospital mortality rates were comparable between neonates with ESBL-GNB and those with non-ESBL GNB, but both were significantly higher than the uninfected controls (both $P<0.001$, respectively, after Bonferroni adjustment). Although the incidence of 
Table 1. Demographic and clinical characteristics of all study subjects, including 77 episodes of ESBL gram-negative bacteremia (GNB) [Case episodes], 316 episodes of non-ESBL GNB bacteremia (Control Group A), and 231 uninfected controls (Control Group B).

\begin{tabular}{|c|c|c|c|c|}
\hline Variable & $\begin{array}{c}\text { Case episodes }(n=77 \\
\text { episodes) }\end{array}$ & $\begin{array}{c}\text { Control group A ( } n=316 \\
\text { episodes) }\end{array}$ & $\begin{array}{c}\text { Control group } B(n=231 \\
\text { patients) }\end{array}$ & $P$ value* \\
\hline Birth weight (g), median (IQR) & $1580(953-2510)$ & $1445(968-2450)$ & $1455(965-2320)$ & $0.790,0.258$ \\
\hline Gestational age (weeks), median (IQR) & $30.0(27.0-37.0)$ & $31.0(27.0-35.8)$ & $31.0(27.0-36.0)$ & $0.838,0.428$ \\
\hline Male gender & $39(50.6)$ & $177(56.0)$ & $132(57.1)$ & $0.444,0.355$ \\
\hline Outborn & $34(44.1)$ & $116(36.7)$ & $71(30.7)$ & $0.241,0.037$ \\
\hline $\begin{array}{l}\text { Age at onset of bacteremia (day), median } \\
\text { (IQR) }\end{array}$ & $28.0(16.0-64.5)$ & $26.0(14.0-50.0)$ & - & $0.149, \mathrm{n} / \mathrm{a}$ \\
\hline Isolates period & & & & $<0.001,1.00$ \\
\hline 2001-2004 & $43(55.8)$ & $98(31.0)$ & $129(55.8)$ & \\
\hline 2005-2012 & $34(44.2)$ & $218(69.0)$ & $102(44.2)$ & \\
\hline \multicolumn{5}{|l|}{ Perinatal history } \\
\hline Birth by cesarean section & $47(61.0)$ & $169(53.5)$ & $156(67.5)$ & $0.350,0.332$ \\
\hline Low Apgar Score at 5 minutes $(\leq 7)$ & $32(41.6)$ & $118(37.3)$ & $66(28.6)$ & $0.515,0.047$ \\
\hline $\begin{array}{l}\text { Prolonged rupture of membrane } \\
\text { (PROM }>18 \text { hours) }\end{array}$ & $16(20.8)$ & $58(18.4)$ & $34(14.7)$ & $0.628,0.216$ \\
\hline Maternal fever or chorioamnionitis & $6(7.8)$ & $16(5.1)$ & $7(3.0)$ & $0.404,0.098$ \\
\hline $\begin{array}{l}\text { Congenital infection and/or early onset } \\
\text { sepsis }\end{array}$ & $4(5.2)$ & $12(3.8)$ & $0(0)$ & $0.529,0.036$ \\
\hline \multicolumn{5}{|l|}{ Underlying chronic condition" } \\
\hline Congenital anomalies $^{¥}$ & $9(11.7)$ & $12(3.8)$ & $4(1.7)$ & $0.010,0.001$ \\
\hline $\begin{array}{l}\text { Neurological sequelae, congenital or } \\
\text { acquired }\end{array}$ & $16(20.8)$ & $46(14.6)$ & $9(3.9)$ & $0.221,<0.001$ \\
\hline Cardiovascular disease ${ }^{\$}$ & $7(9.1)$ & $15(4.7)$ & $18(7.8)$ & $0.223,0.810$ \\
\hline Bronchopulmonary dysplasia & $11(14.3)$ & $91(28.8)$ & $61(26.4)$ & $0.009,0.030$ \\
\hline $\begin{array}{l}\text { Pulmonary hypertension and/or cor } \\
\text { pulmonale }\end{array}$ & $1(1.3)$ & $4(1.3)$ & $9(3.9)$ & $0.982,0.461$ \\
\hline Congenital gastrointestinal tract pathology & $7(9.1)$ & $23(7.3)$ & $5(2.2)$ & $0.632,0.013$ \\
\hline Gastrointestinal sequelae $^{* *}$ & $10(13.0)$ & $17(5.4)$ & $6(2.6)$ & $0.025,0.001$ \\
\hline Renal disease ${ }^{\&}$ & $9(11.7)$ & $6(1.9)$ & $0(0)$ & $<0.001,<0.001$ \\
\hline Surgical history (within one month) ${ }^{€}$ & $8(10.4)$ & $26(8.2)$ & $16(6.9)$ & $0.505,0.331$ \\
\hline Use of corticosteroid (within one month) ${ }^{€}$ & $6(7.8)$ & $24(7.6)$ & $20(8.8)$ & $0.953,0.813$ \\
\hline Invasive mechanical ventilation (intubation) ${ }^{€}$ & $58(75.3)$ & $250(79.1)$ & $157(68.0)$ & $0.796,0.343$ \\
\hline On high frequency oscillatory ventilator ${ }^{€}$ & $7(9.1)$ & $17(5.6)$ & $30(13.0)$ & $0.223,0.362$ \\
\hline Use of TPN and/or intrafat ${ }^{€}$ & $70(90.9)$ & $269(85.1)$ & $182(78.8)$ & $0.267,0.017$ \\
\hline Use of central venous catheter ${ }^{€}$ & $73(94.8)$ & $282(89.2)$ & $186(80.5)$ & $0.195,0.002$ \\
\hline \multicolumn{5}{|l|}{$\begin{array}{l}\text { Antibiotic exposure (within } 30 \text { days before } \\
\text { bacteremia) })^{€}\end{array}$} \\
\hline $3^{\text {rd }}$ generation cephalosporin & $53(68.8)$ & $78(24.7)$ & $85(36.8)$ & $<0.001,<0.001$ \\
\hline Vancomycin or Teicoplanin & $34(64.1)$ & $65(20.6)$ & $72(31.2)$ & $<0.001,0.052$ \\
\hline Carbapenem & $12(15.6)$ & $21(6.6)$ & $10(4.3)$ & $0.020,0.003$ \\
\hline Monobactam & $3(3.9)$ & $17(5.4)$ & $4(1.7)$ & $0.595,0.270$ \\
\hline Aminoglycoside & $51(66.2)$ & $173(54.7)$ & $193(83.5)$ & $0.073,0.002$ \\
\hline Anti-fungal drugs & $4(5.2)$ & $4(1.3)$ & $3(1.3)$ & $0.029,0.068$ \\
\hline Anti-anaerobes antibiotics (metronidazole) & $14(18.2)$ & $12(3.8)$ & $6(2.6)$ & $<0.001,<0.001$ \\
\hline Episode of bacteremia & & & & $0.125, \mathrm{n} / \mathrm{a}$ \\
\hline First episode & $60(77.9)$ & $269(85.1)$ & - & \\
\hline Recurrent episode & $17(22.1)$ & $47(14.9)$ & - & \\
\hline Duration of TPN and/or intrafat ${ }^{\#}$ & $31.0(12.0-56.0)$ & $25.0(12.0-53.8)$ & $11.0(5.0-19.0)$ & $0.510,<0.001$ \\
\hline
\end{tabular}

(Continued) 
Table 1. (Continued)

\begin{tabular}{|c|c|c|c|c|}
\hline Variable & $\begin{array}{c}\text { Case episodes }(n=77 \\
\text { episodes) }\end{array}$ & $\begin{array}{c}\text { Control group A ( } n=316 \\
\text { episodes) }\end{array}$ & $\begin{array}{c}\text { Control group } B(n=231 \\
\text { patients) }\end{array}$ & $P$ value* \\
\hline Duration of ventilator use ${ }^{\#}$ & $27.0(9.0-61.0)$ & $26.0(7.3-63.0)$ & $16.0(4.0-46.0)$ & $0.890,<0.001$ \\
\hline Duration of intubation ${ }^{\#}$ & $20.0(4.0-45.0)$ & $17.0(3.0-46.0)$ & $6.0(0-25.0)$ & $0.124,<0.001$ \\
\hline Duration of central venous catheter use ${ }^{\#}$ & $44.0(25.0-68.0)$ & $35.0(20.0-63.5)$ & $13.0(5.0-24.0)$ & $0.074,<0.001$ \\
\hline Duration of hospital stay ${ }^{\#}$ & $71.0(43.0-110)$ & $64.0(36.0-102)$ & $45.0(28.0-74.0)$ & $0.433,<0.001$ \\
\hline Overall in-hospital mortality ${ }^{\#}$ & $14 / 71(19.7)$ & $36 / 289(12.5)$ & 9/231 (3.9) & $0.126,<0.001$ \\
\hline
\end{tabular}

All data were expressed as number (percentage \%), unless indicated otherwise; IQR: interquartile range; TPN: total parenternal nutrition; n/a: not available. ${ }^{*} P$ values were expressed as comparisons between (Case episodes and Control group A, Case episodes and Control group B).

"Data were 71 unique patients with ESBL GNB and 289 unique patients with non-ESBL GNB.

"At onset of Gram-negative (both ESBL and non-ESBL) bacteremia, and during the total hospital stay for control group B, one patient may have more than one chronic conditions.

€One month before onset of Gram-negative (both ESBL and non-ESBL) bacteremia, and during the total hospital stay for control group B.

${ }^{*}$ Included all documented and undocumented syndrome, chromosome anomalies, genetic or metabolic disorder, but not simple cleft palate or polydactyly.

$\$$ Including patients with complicated congenital heart disease and acyanotic heart disease with heart failure sign.

* Including short bowel syndrome, GI pseudo-obstruction, adhesion ileus, hepatic failure and chronic malnutrition.

${ }^{\&}$ Including congenital nephrotic syndrome, chronic renal insufficiency, renal failure requiring hemodialysis and IgA nephropathy.

doi:10.1371/journal.pone.0159744.t001

ESBL-GNB significantly decreased after early 2005, the clinical features and prognosis did not change over time (a sepsis-attributable mortality rate of $16.3 \%$ before 2004 vs. $14.7 \%$ after 2005, other comparisons were not shown). However, the ESBL-producing isolates showed a significantly higher antimicrobial resistant rate to gentamicin and amikacin before 2004 (97.7\% and $88.4 \%$ vs. $58.8 \%$ and $38.2 \%$, respectively, both $P<0.001$ ) than after 2005 .

The results of univariate and multivariate analyses of risk factors potentially associated with in-hospital mortality are summarized in Table 4 . Neonates with lower birth weight or gestational age and those with low apgar score at 5 minutes were at significantly higher risk of mortality, so were female infants when compared with male infants. Risk factors for overall mortality included neonates with ESBL-GNB (when compared with uninfected controls) and several underlying chronic conditions. After adjusting for all variables, neonates with lower gestational age (also lower birth weight), underlying secondary pulmonary hypertension with/ without cor pulmonale (odds ratio [OR], 7.22; 95\% confidence interval: $2.17-24.06 ; P=0.001$ ) and infectious complications after bacteremia (OR, 6.66; 95\% CI: 2.88-15.40; $P<0.001)$ were found to be at independently increased risk for final mortality.

\section{Microbiological results}

Of the 61 isolates with identifiable ESBLs, SHV-type family accounted for 41 (67.2\%) ESBLs, CTX-M for 23 (37.7\%), and a TEM-type for 2 isolates (3.3\%) (Table 5). Eight isolates produced 2 kinds of ESBLs. We found no significant differences in epidemiological or clinical characteristics by type of ESBL produced (data not shown). Susceptibility results are also shown in Table 5. More than two-third of all isolates showed resistance to aminoglycosides and trimethoprim-sulfamethoxazole, but fluoroquinolone resistance was noted in only $8(10.4 \%)$ isolates. All isolates were considered to be multidrug resistant [30], and 14 (18.2) showed resistance to all $\beta$-lactam/ $\beta$-lactamase inhibitor combination.

With regard to clonality, majority of the isolates were clonally unrelated. Five small clusters of clonally related isolates were found by molecular methods. These included $4 \mathrm{SHV}$-1-producing K. pneumoniae between June 2009 and December 2009, 3 CTX-M27-producing E. coli 
Table 2. Multivariate analysis of risk factors for neonatal late-onset bloodstream infection due to Extended-spectrum $\beta$-lactamase (ESBL)-producing Gram-negative bacilli (GNB).

\begin{tabular}{|c|c|c|c|c|}
\hline \multirow{2}{*}{$\begin{array}{l}\text { Control group } \\
\text { Risk factor }\end{array}$} & \multicolumn{2}{|c|}{ non-ESBL GNB neonates population } & \multicolumn{2}{|c|}{ base population of hospitalized neonates } \\
\hline & adjusted OR (95\% Cl) & $P$ value & adjusted OR (95\% Cl) & $P$ value \\
\hline Outborn & - & - & $2.23(1.19-4.19)$ & 0.013 \\
\hline Low apgar score at 5 minute $(\leq 7)$ & - & - & $0.84(0.42-1.68)$ & 0.616 \\
\hline \multicolumn{5}{|l|}{ Underlying chronic conditions" } \\
\hline Congenital anomalies & $2.09(0.64-6.83)$ & 0.225 & $3.33(0.73-15.24)$ & 0.121 \\
\hline Neurological comorbidities & - & - & $4.37(1.52-12.58)$ & 0.006 \\
\hline Congenital GI tract pathology & - & - & $0.94(0.20-4.50)$ & 0.939 \\
\hline Gastrointestinal sequelae & $1.55(0.58-4.22)$ & 0.394 & $2.38(0.61-9.40)$ & 0.213 \\
\hline Renal disease & $5.18(1.37-19.52)$ & 0.015 & $4.07(1.10-15.08)$ & 0.035 \\
\hline Use of TPN and/or intrafat* & - & - & $3.88(0.62-24.48)$ & 0.482 \\
\hline Use of central venous catheter* & - & - & $0.57(0.12-2.73)$ & 0.148 \\
\hline Previous antibiotic exposure* & - & - & & \\
\hline $3^{\text {rd }}$ generation cephalosporin & $6.88(3.53-13.38)$ & $<0.001$ & $4.72(2.03-10.97)$ & $<0.001$ \\
\hline Vancomycin or teicoplanin & $1.19(0.60-2.37)$ & 0.619 & $3.27(1.36-7.87)$ & 0.008 \\
\hline Aminoglycoside & $3.13(1.66-5.89)$ & $<0.001$ & - & - \\
\hline Carbapenem & $1.42(0.53-3.80)$ & 0.492 & $2.01(0.65-6.27)$ & 0.228 \\
\hline Anti-fungal drugs & $0.97(0.19-4.99)$ & 0.968 & $1.80(0.25-13.04)$ & 0.560 \\
\hline Anti-anaerobes antibiotics (metronidazole) & $2.06(0.74-5.78)$ & 0.169 & $5.91(1.81-19.31)$ & 0.003 \\
\hline
\end{tabular}

"At onset of Gram-negative (both ESBL and non-ESBL) bacteremia, and during the total hospital stay for control group B, one patient may have more than one chronic conditions, Each patient with an underlying chronic condition is compared with those without that specific condition.

*One month before onset of Gram-negative (both ESBL and non-ESBL) bacteremia, and during the total hospital stay for base population of hospitalized neonates (control group B).

ESBL: Extended-spectrum $\beta$-lactamase; GNB: Gram-negative bacilli; HFOV: high frequency oscillatory ventilator; OR: odds ratio; 95\% Cl: 95\% confidence interval; TPN: total parenteral nutrition.

doi:10.1371/journal.pone.0159744.t002

between February 2012 and March 2012, 2 CTX-M27+CMY-2 producing E. coli between December 2010 and January 2011, 2 SHV-12-producing K. pneumoniae between February 2006 and December 2006, and 2 CTX-M3-producing K. oxytoca between August 2002 and September 2002.

\section{Discussion}

Results from this study demonstrated that exposure to third generation cephalosporin within one month before onset of BSIs and presence of underlying renal disease were independent risk factors for acquisition of ESBL-GNB. Although the frequency of occurrence may seem decreasing recently, ESBL-GNB had a higher severity of illness, more severe clinical manifestations, and more frequently required blood transfusions and mechanical support when compared with their antibiotic-susceptible counterparts. Delayed appropriate antibiotics were more frequently encountered in neonates with ESBL-GNB, and ESBL-GNB was therefore associated with a significantly higher rate of infectious complications and sepsis-attributable mortality than non-ESBL GNB.

An appropriate design for investigating risk factors for infection due to antibiotic-resistant organisms should consider more closely the optimization of control group selection and adjusting for confounding caused by time at risk and comorbid illness [31,32]. The preferred control group should be capable of representing the source or base population or underlying cohort. The shortcoming of enrolling only patients with susceptible organisms as the controls is the biased 
Table 3. Clinical manifestations, treatment and outcomes of extended-spectrum $\beta$-lactamase producing Gram-negative bacteremia (ESBL-GNB) compared with non-ESBL GNB.

\begin{tabular}{|c|c|c|c|}
\hline & ESBL-GNB ( $n=77$ episodes) & Non-ESBL GNB ( $n=316$ episodes) & $P$ value \\
\hline \multicolumn{4}{|l|}{ Clinical manifestations } \\
\hline Prolonged feeding intolerance (> 3 days) & $44(57.1)$ & $108(33.6)$ & $<0.001$ \\
\hline Coagulopathy and/or GI bleeding & $31(40.3)$ & $93(23.6)$ & 0.076 \\
\hline Disseminated intravascular coagulopathy & $21(15.3)$ & $42(8.4)$ & 0.005 \\
\hline Septic shock & $23(29.9)$ & $61(19.3)$ & 0.062 \\
\hline \multicolumn{4}{|l|}{ Laboratory characteristics } \\
\hline Leukopenia (WBC count < 4,000/uL) & $18(23.4)$ & $74(23.4)$ & 0.983 \\
\hline Leukocytosis (WBC count > 20,000/uL) & $28(36.4)$ & $89(28.2)$ & 0.167 \\
\hline WBC shift to left (immature WBC $\geq 20 \%$ total WBC) & $29(37.7)$ & $75(23.7)$ & 0.021 \\
\hline Anemia (hemoglobin $<11.0 \mathrm{mg} / \mathrm{dL}$ ) & $49(63.6)$ & $153(48.4)$ & 0.022 \\
\hline Thrombocytopenia (platelet < 80,000/uL) & $47(61.0)$ & $148(46.8)$ & 0.031 \\
\hline C-reactive protein ${ }^{\&}(\mathrm{mg} / \mathrm{dL})$, median (IQR) & $70.5(29.7-141.5)$ & $63.3(18.6-121.5)$ & 0.130 \\
\hline Metabolic acidosis requiring jusomin replacement & $33(42.9)$ & $80(25.3)$ & 0.003 \\
\hline NTISS score at most severe day of bacteremia, mean \pm SD & $18.0 \pm 5.5$ & $16.5 \pm 5.0$ & 0.023 \\
\hline Empirical antibiotic treatment & & & 0.865 \\
\hline Combination therapy & $73(94.8)$ & $303(95.9)$ & \\
\hline$\beta$-lactam + aminoglycoside & $13(16.9)$ & $48(15.2)$ & \\
\hline$\beta$-lactam $+3^{\text {rd }}$ generation cephalosporin & $17(22.1)$ & $59(18.7)$ & \\
\hline Glycopeptide + aminoglycoside & $2(2.6)$ & $12(3.8)$ & \\
\hline Glycopeptide $+3^{\text {rd }}$ generation cephalosporin & $27(35.1)$ & $125(39.6)$ & \\
\hline Glycopeptide + Carbapenem & $7(9.1)$ & $24(7.8)$ & \\
\hline Above combination + anti-anaerobes (metronidazole) & $7(9.1)$ & $35(11.1)$ & \\
\hline Monotherapy & $4(5.2)$ & $13(4.1)$ & \\
\hline $3^{\text {rd }}$ generation cephalosporin & $2(2.6)$ & $6(1.9)$ & \\
\hline Carbapenem & $2(2.6)$ & $3(0.9)$ & \\
\hline Glycopeptide & $0(0)$ & $4(1.3)$ & \\
\hline Inadequate antibiotics within 24 hours after bacteremia onset & $59(76.6)$ & $30(9.5)$ & $<0.001$ \\
\hline Removal of central venous catheters & $21 / 67(31.3)$ & $84 / 256(32.8)$ & 0.884 \\
\hline Requirement of blood transfusion(s) & $62(80.5)$ & $191(60.4)$ & 0.001 \\
\hline Required intubation/ventilator support with HFOV & $36(46.8) / 8(10.4)$ & $125(39.5) / 22(7.0)$ & $0.301 / 0.310$ \\
\hline \multicolumn{4}{|l|}{ Outcomes } \\
\hline Infectious complications* & $16(20.8)$ & $29(9.2)$ & 0.008 \\
\hline Persistent bacteremia & $7(9.1)$ & $11(3.5)$ & 0.071 \\
\hline Sepsis attributable mortality & $12(15.6)$ & $25(7.9)$ & 0.049 \\
\hline
\end{tabular}

All data were expressed as number (percentage \%), unless indicated otherwise; WBC: white blood cell, NTISS: Neonatal Therapeutic Intervention Scoring System, NEC: necrotizing enterocolitis, IQR: interquartile range, HFOV: high frequency oscillatory ventilator.

${ }^{\&} \mathrm{CRP}$ normal range: $<5 \mathrm{mg} / \mathrm{dL}$.

*Infectious complications were defined as a newly infectious focus or persistent organ dysfunction which occurred within one week and directed related to bacteremia, but not concurrently at onset of bacteremia.

"Persistent bacteremia was defined as 2 or more consecutive positive blood cultures, at least 48 hours apart, during a single sepsis episode.

doi:10.1371/journal.pone.0159744.t003

overestimate of relative risk due to exposure to active antibiotics [31], which was reflected in the finding of gentamicin as the independent risk factor when only the antibiotic-susceptible group was compared. In order to eliminate the possible effects of changing practice policies over time, the second controls were randomly selected from the same distinct source (the same NICU at the same period). Furthermore, previous studies investigating risk factors for ESBL-GNB in the NICU were 
Table 4. Risk factors for in-hospital mortality of the 583 study subjects (including 71 patients with ESBL GNB, 289 patients with non-ESBL GNB, and 231 controls) by univariate and multivariate analysis.

\begin{tabular}{|c|c|c|c|c|c|}
\hline \multirow[t]{2}{*}{ Risk factor } & \multirow[t]{2}{*}{ Survived, $N=524, n(\%)$} & \multirow[t]{2}{*}{ Died, $N=59, n(\%)$} & \multirow[t]{2}{*}{$P$ value } & \multicolumn{2}{|c|}{ Multivariate analysis } \\
\hline & & & & Adjusted OR (95\% Cl) & $P$ value \\
\hline Gestational age (weeks), median (IQR) & $31.0(28.0-35.0)$ & $27.0(24.0-34.0)$ & $<0.001$ & $1.26(1.03-1.56)^{*}$ & 0.028 \\
\hline Birth body weight (g), median (IQR) & $1495.0(1040.0-2285.0)$ & $956.0(698.0-1660.0)$ & $<0.001$ & & \\
\hline Male sex & $302(57.6)$ & $25(42.4)$ & 0.038 & $1.46(0.73-2.92)$ & 0.283 \\
\hline Outborn & $194(37.0)$ & $15(25.4)$ & 0.114 & & \\
\hline Low apgar score at 5 minutes $(\leq 7)$ & $164(31.3)$ & $33(55.9)$ & $<0.001$ & $1.01(0.46-2.23)$ & 0.978 \\
\hline Study period & & & 0.321 & & \\
\hline 2001-2004 & $228(43.5)$ & $21(35.6)$ & & & \\
\hline 2005-2012 & $296(56.5)$ & $38(64.4)$ & & & \\
\hline \multicolumn{6}{|l|}{ Underlying chronic conditions } \\
\hline Congenital anomalies & $20(3.8)$ & $4(6.8)$ & 0.266 & & \\
\hline Neurological sequelae & $49(9.4)$ & $14(23.7)$ & 0.003 & $1.86(0.81-4.28)$ & 0.142 \\
\hline Cardiovascular disease & $18(3.4)$ & $10(16.9)$ & $<0.001$ & $2.53(0.46-13.94)$ & 0.288 \\
\hline Bronchopulmonary dysplasia & $122(23.3)$ & $29(49.2)$ & $<0.001$ & $2.06(0.88-4.82)$ & 0.094 \\
\hline Pulmonary hypertension & $4(0.8)$ & $9(15.3)$ & $<0.001$ & $7.22(2.17-24.06)$ & 0.001 \\
\hline Gastrointestinal sequelae & $25(4.8)$ & $6(10.2)$ & 0.074 & & \\
\hline Renal disease & $5(1.0)$ & $7(11.9)$ & $<0.001$ & $6.40(0.56-32.89)$ & 0.135 \\
\hline Pathogens & & & $<0.001$ & & \\
\hline Controls & $222(42.4)$ & $9(15.5)$ & & & \\
\hline Neonates with non-ESBL GNB & $253(48.3)$ & $36(61.0)$ & & 1 (references) & \\
\hline Neonates with ESBL GNB & $57(10.9)$ & $14(23.7)$ & & $1.48(0.64-3.45)$ & 0.365 \\
\hline Initial inadequate antibiotics & $71 / 310(22.9)$ & $15 / 50(30.0)$ & 0.287 & & \\
\hline Infectious complications & $22 / 310(6.1)$ & $15 / 50(30.0)$ & $<0.001$ & $6.66(2.88-15.40)$ & $<0.001$ \\
\hline
\end{tabular}

IQR: interquartile range; ESBL-GNB: Extended-spectrum $\beta$-lactamase-producing Gram-negative bacteremia; OR: odds ratio, 95\% CI: 95\% confidence interval.

*Every two weeks of gestational age decrement. Because of the strong correlation between birth weight and gestational age, only the risk factor of gestational age was enrolled into the multivariate analysis.

doi:10.1371/journal.pone.0159744.t004 
Table 5. Distribution of $\beta$-lactamase genes and major antimicrobial susceptibility pattern of 77 ESBL-producing gram-negative bacteria.

\begin{tabular}{|c|c|c|c|c|c|}
\hline Gene/microorganisms & $\begin{array}{l}\text { E. coli (total } \\
n=16)\end{array}$ & $\begin{array}{l}\text { K. pneumonia (total } \\
n=40 \text { ) }\end{array}$ & $\begin{array}{c}\text { K. oxytoca (total } \\
n=8 \text { ) }\end{array}$ & $\begin{array}{l}\text { Enterob. spp. * (total } \\
\mathrm{n}=13 \text { ) }\end{array}$ & $\begin{array}{c}\text { Total (total } \\
\mathbf{n}=\mathbf{7 7} \text { ) }\end{array}$ \\
\hline SHV 1 & - & 7 & - & 1 & 8 \\
\hline 2 & - & 1 & - & 1 & 2 \\
\hline $2 \mathrm{~A}$ & - & 2 & 1 & - & 3 \\
\hline 11 & - & 4 & - & - & 4 \\
\hline 12 & - & 10 & 1 & 8 & 19 \\
\hline СТХ МЗ & 2 & 1 & 4 & 1 & 8 \\
\hline M14 & 2 & - & - & - & 2 \\
\hline M27 & 5 & - & - & - & 5 \\
\hline M55/M57 & 1 & - & - & - & 1 \\
\hline TEM 1 & 1 & - & - & - & 1 \\
\hline TEM-1 + SHV-12 & - & - & - & 1 & 1 \\
\hline CTX-M3+SHV-1 & - & 4 & - & - & 4 \\
\hline CTX-M14+DHA-1 & - & - & 1 & - & 1 \\
\hline CTX-M27+CMY-2 & 2 & - & - & - & 2 \\
\hline Unidentified & 3 & 11 & 1 & 1 & 16 \\
\hline \multicolumn{6}{|l|}{ Isolates period } \\
\hline 2001-2004 & 8 & 23 & 5 & 7 & 43 \\
\hline 2005-2012 & 8 & 17 & 3 & 6 & 34 \\
\hline $\begin{array}{l}\text { Antimicrobial susceptibility } \\
\text { patterns" }\end{array}$ & \multicolumn{2}{|c|}{ No. (\%) of susceptible isolates } & & & \\
\hline Ceftriaxone/Cefotaxime & $0 / 16(0)$ & $0 / 40(0)$ & $0 / 8(0)$ & $0 / 13(0)$ & $0 / 77(0)$ \\
\hline Ceftazidime & $1 / 16(6.3)$ & $2 / 40(5.0)$ & $3 / 8(37.5)$ & $1 / 13(7.6)$ & $7 / 77(9.1)$ \\
\hline Amoxicillin-clavulanate & $7 / 16(43.8)$ & $34 / 40(85.0)$ & $6 / 8(75.0)$ & $6 / 13(46.2)$ & $53 / 77(68.8)$ \\
\hline Piperacillin-tazobactam & $12 / 12(100)$ & $32 / 36(88.9)$ & $2 / 5(40.0)$ & $6 / 7(85.7)$ & $52 / 60(86.7)$ \\
\hline Imipenem/Meropenem & $16 / 16(100)$ & $40 / 40(100)$ & $8 / 8(100)$ & $13 / 13(100)$ & $77 / 77(100)$ \\
\hline Ciprofloxacin & 9/16 (56.3) & $39 / 40(97.5)$ & $8 / 8(100)$ & $13 / 13(100)$ & $69 / 77(89.6)$ \\
\hline Amikacin & $13 / 16(81.3)$ & $11 / 40(27.5)$ & $1 / 8(12.5)$ & $1 / 13(7.6)$ & $26 / 77(33.8)$ \\
\hline Gentamicin & $7 / 16(43.8)$ & $7 / 40(17.5)$ & $1 / 8(12.5)$ & $0 / 13(0)$ & 15/77 (19.5) \\
\hline Aztreonam & $0 / 8(0)$ & $0 / 30(0)$ & $1 / 6(16.7)$ & $0 / 13(0)$ & $1 / 57(1.8)$ \\
\hline Flomoxef & $13 / 13(100)$ & $31 / 32(96.9)$ & $5 / 5(100)$ & $2 / 8(25.0)$ & $51 / 57(87.9)$ \\
\hline Trimethoprim-sulfamethoxazole & $1 / 6(16.7)$ & $8 / 26(30.8)$ & $1 / 5(20.0)$ & $0 / 12(0)$ & $10 / 49(20.4)$ \\
\hline
\end{tabular}

*Including 12 Enterob. cloacae isolates and one Enterob. aerogenes isolate.

"Some of the antimicrobial susceptibilities were not performed, and the resistances to cephalosporin were interpreted according to Clinical and Laboratory Standards Institute recommendation.

doi:10.1371/journal.pone.0159744.t005

spectrum and time to prior antibiotic exposure. Therefore, we can have better prediction of drug-resistance bacteria when clinical sepsis is encountered.

In general, bacteria that produce ESBLs to cause antimicrobial resistance are not more virulent than their antibiotic-susceptible counterparts. However, delay in initiating appropriate antibiotics, which is significantly frequently seen in patients with ESBL-GNB, was thought to be an important contributory factor towards final adverse outcomes [38,39]. From this study, we assume that ESBLs significantly cause delay of initiating effective antibiotics, which resulted in progression or persistence of septic symptoms, and then subsequently the occurrence of infectious complications. We found that neither ESBL-GNB nor inappropriate empiric antibiotic was the independent risk factor for mortality. There were other factors that contributed 
independently to final mortality, such as occurrence of infectious complications or underlying chronic diseases [23,24].

In our NICU, only $10.4 \%$ of the ESBL isolates presented resistance to fluoroquinolones, but most $(>70 \%)$ were resistant to aminoglycosides and trimethoprim/sulfamethoxazole. These results seem compatible with our antibiotic policies in the NICU, since third-generation cephalosporins and aminoglycosides were significantly more frequent prescribed than quinolones were. Literature review showed that ESBLs from different sources often show different antibiotic susceptibility patterns $[3,34,40-42]$.

A significant decrease in ESBL-GNB was noted since early 2005, which may be associated with the reinforcement of hand hygiene, implementation of alcohol-based handrub and augmentation of aseptic care cover since 2003 to 2004. In our NICU, the nosocomial infection rate was reduced since the end of 2004 [43], which may result in the decrease of antibiotic usage and then the emergence of ESBL-GNB. The molecular data also showed that most ESBL-associated bacteremias were caused by clonally unrelated strains. Several episodes of ESBL-GNB occurred sporadically in a previously healthy patient without any identifiable risk factors, whom might possibly be transmitted from the environment or contaminated hands of healthcare workers [11]. It cannot be overemphasized again that hand hygiene can reduce healthcare-associated infections, including those caused by ESBL-producing bacteria.

In contrast to recent studies that have demonstrated CTX-M enzymes as the predominant ESBLs in all Europe, Canada, South America, and Asia [29,42,44,45], the main enzymes characterized in our NICUs were SHV enzymes, especially SHV-12. However, we noticed an obvious trend between different ESBLs and bacteraemic isolates of Enterobactericeae in our NICUs. Taking together, we may assume that CTX-M-type ESBLs are now prevalent in most countries [44,45]. In Klebsiella spp. and Enterobacter spp., SHV was still the most common ESBL type, but CTX-M-type ESBLs were also present in both organisms.

There are some limitations in this study. Given the extended period of study subjects and retrospective nature, the changing incidence and clinical practices over time can be the biases to our results. Our study population was from a single medical center, and the results may be less generalizable than those from multicenter and prospective observational design. In the outcome analysis, the number of events (ie, deaths) was low, which limited the power of the multivariate analysis. Finally, the scope of molecular epidemiological studies was limited, and a prospective surveillance study should be considered in future investigations.

\section{Acknowledgments}

All authors thank Mrs. Chiao-Ching Chiang for keeping the database of our NICU, and all nursing staff working in our NICUs for keeping extremely detailed patient records, which contributed greatly to the completion of this research. We want to thank Miss Chun-Chun Cheng and Mr. Yu-Jr Lin for statistical consultation

\section{Author Contributions}

Conceived and designed the experiments: JFH SMC HRH RL.

Performed the experiments: JFH ITL MCC RHF.

Analyzed the data: JFH SMC MHT ITL.

Contributed reagents/materials/analysis tools: JFH SMC ITL MHT.

Wrote the paper: ITL MHT. 
Critically reviewed the manuscript: JFH YCH. Revised the manuscript: JFH YCH. Approved the final manuscript as submitted: JFH YCH. Read and approved the final manuscript: MHT ITL SMC RL MCC RHF HRH JFH YCH.

\section{References}

1. Hsu JF, Chu SM, Huang YC, Lien R, Huang HR, Lee CW, et al. (2015) Predictors of clinical and microbiological treatment failure in neonatal bloodstream infections. Clin Microbiol Infect 21:482.e9-482. e17.

2. Tsai MH, Chu SM, Lee CW, Hsu JF, Huang HR, Chiang MC, et al. (2014) Recurrent late-onset sepsis in the neonatal intensive care unit: incidence, clinical characteristics, and risk factors. Clin Microbiol Infect 20:0928-0925. doi: 10.1111/1469-0691.12661 PMID: 24796697

3. Badal RE, Bouchillon SK, Lob SK, Hackel MA, Hawser SP, Hoban DJ (2013) Etiology, Extended-spectrum $\beta$-lactamase rates, and antimicrobial susceptibility of Gram-negative bacilli causing intra-abdominal infections in patients in general pediatric and pediatric intensive care units-Global data from the study for monitoring antimicrobial resistance trends (SMART) 2008-2010. Pediatr Infect Dis J 32:636640. doi: 10.1097/INF.0b013e3182886377 PMID: 23838732

4. Katsuta T, Shoji K, Watanabe Y, Saitoh A (2013) Treatment of pyelonephritis caused by extendedspectrum $\beta$-lactamase-producing enterobacteriaceae in children. Pediatr Infect Dis J 32:417-419. doi: 10.1097/INF.0b013e318284b1e8 PMID: 23274920

5. Wójkowska-Mach J, Chmielarczyk A, Borszewska-Kornacka M, Domanska J, Gadzinowski J, Gulczynska E, et al. (2013) Enterobacteriaceae infections of very low birth weight infants in Polish Neonatal Intensive Care Units: Resistance and Cross-transmission. Pediatr Infect Dis J 32:594-598. doi: 10. 1097/INF.0b013e318287fe2a PMID: 23411624

6. Löhr IH, Rettedal S, Natas OB, Naseer U, Oymar K, Sundsfjord A (2013) Long-term fecal carriage in infants and intra-household transmission of CTX-M-15 producing Klebsiella pneumoniae following a nosocomial outbreak. J Antimicrob Chemother 68:1043-1048. doi: 10.1093/jac/dks502 PMID: 23288401

7. Oteo J, Cercenado E, Fernández-Romero S, Saéz D, Padilla B, Zamora E, et al. (2012) Extendedspectrum- $\beta$-lactamase producing Escherichia coli as a cause of pediatric infection: report of a neonatal intensve care unit outbreak due to a CTX-M-14-producing strain. Antimicro Agents Chemother 56:5458.

8. Paterson DL, Bonomo RA (2005) Extended-spectrum- $\beta$-lactamases: a clinical update. Clin Microbiol Rev 18:657-686. PMID: 16223952

9. Cantey JB, Sreeramoju P, Jaleel M, Treviño S, Gander R, Hynan LS, et al. (2013) Prompt control of outbreak caused by Extended-spectrum $\beta$-lactamase producing Klebsiella pneumoniae in a neonatal intensive care unit. J Pediatr 163:672-679. doi: 10.1016/j.jpeds.2013.03.001 PMID: 23582136

10. Bagattini M, Crivaro V, Di Popolo A, Gentile F, Scarcella A, Triassi M, et al. (2006) Molecular epidemiology of extended-spectrum beta-lactamase-producing Klebsiella pneumoniae in a neonatal intensive care unit. J Antimicrob Chemother 57:979-982. PMID: 16531430

11. Somily AM, Alsubaie SS, BinSaeed AA, Torchyan AA, Alzamil FA, Al-Aska Al, et al. (2014) Extendedspectrum $\beta$-lactamase-producing Klebsiella pneumonia in the neonatal intensive care unit: does vancomycin play a role? Am J Infect Control 42:277-82. doi: 10.1016/j.ajic.2013.09.028 PMID: 24581016

12. Giuffré $M$, Cipolla D, Bonura $C$, Geraci DM, Aleo A, Di Noto $S$, et al. (2013) Outbreak of colonization by Extended-spectrum $\beta$-lactamase Escherichia coli sequence type 131 in a neonatal intensive care unit, Italy. Antimicrob Resist Infect Control 2:8 doi: 10.1186/2047-2994-2-8 PMID: 23517816

13. Shakil S, Akram M, Ali SM, Khan AU (2010) Acquisition of Extended-spectrum $\beta$-lactamase producing Escherichia coli strains in male and female infants admitted to a neonatal intensive care unit: molecular epidemiology and analysis of risk factors. J Med Microbiol 59:948-954. doi: 10.1099/jmm.0.020214-0 PMID: 20430903

14. Singh N, Patel KM, Léger MM, Short B, Sprague BM, Kalu N, et al (2002) Risk of resistant infections with Enterobacteriaceae in hospitalized neonates. Pediatric Infect Dis J 21:1029-1033.

15. Linkin DR, Fishman NO, Patel JB, Merrill JD, Lautenbach E (2004) Risk factors for extended-spectrum beta-lactamase-producing Enterobacteriaceae in a neonatal intensive care unit. Infect Control Hosp Epidemiol 25:781-783. PMID: 15484805

16. Le J, Nguyen T, Okamoto M, McKamy S, Lieberman JM (2008) Impact of empiric antibiotic use on development of infections caused by extended-spectrum beta-lactamase bacteria in a neonatal intensive care unit. Pediatric Infect Dis J 27:314-318. 
17. Crivaro V, Bagattini M, Salza MF, Raimondi F, Rossano F, Triassi M, et al. (2007) Risk factors for extended-spectrum beta-lactamase-producing Serratia marcescens and Klebsiella pneumoniae acquisition in a neonatal intensive care unit. J Hosp Infect 67:135-141. PMID: 17884248

18. Huang Y, Zhuang S, Du M (2007) Risk factors of nosocomial infection with extended-spectrum betalactamase-producing bacteria in a neonatal intensive care unit in China. Infection 35:339-345. PMID: 17721736

19. Kaye KS, Harris AD, Samore M, Carmeli Y (2005) The case-case-control study design: adressing the limitations of risk factor studies for antimicrobial resistance. Infect Control Hosp Epidemiol 26:346351. PMID: 15865269

20. Horan TC, Andrus M, Dudeck MA (2008) CDC/NHSN surveillance definition of health care-associated infection and criteria for specific types of infections in the acute care setting. Am J Infect Control 36:309-332. doi: 10.1016/j.ajic.2008.03.002 PMID: 18538699

21. Gleason CA, Devaskar SU. Avery's Disease of the Newborn. $9^{\text {th }}$ ed. Philadelphia, PA: Elsevier Saunders; 2011.

22. Kermorvant-Duchemin E, Laborie S, Rabilloud M, Lapillonne A, Claris O (2008) Outcome and prognostic factors in neonates with septic shock. Pediatr Crit Care Med 9:186-191. doi: 10.1097/PCC. Ob013e31816689a8 PMID: 18477932

23. Tsai MH, Hsu JF, Chu SM, Lien R, Huang HR, Chiang MC, et al. (2014) Incidence, clinical characteristics and risk factors for adverse outcome in neonates with late-onset sepsis. Pediatr Infect Dis J 33:e7e13. doi: 10.1097/INF.0b013e3182a72ee0 PMID: 23899966

24. Tsai MH, Chu SM, Hsu JF Lien R, Huang HR, Chiang MC, et al. (2014) Risk factors and outcomes for multidrug-resistant gram-negative bacteremia in the NICU. Pediatrics 133:e322-e329. doi: 10.1542/ peds.2013-1248 PMID: 24420803

25. Gray JE, Richardson DK, McCormick MC, Workman-Daniels K, Goldmann DA (1992) Neonatal therapeutic intervention scoring system: a therapy-based severity-of-illness index. Pediatrics 90:561-567. PMID: 1408510

26. Clinical and Laboratory Standards Institute. Performance Standards for Antimicrobial Susceptibility Testing: Twenty-second Informational Supplement M100-S22. CLSI, Wayne, PA, USA, 2012.

27. Clinical and Laboratory Standards Institute. Performance Standards for Antimicrobial Disk Susceptibility Tests: Approved Standard-Tenth Informational Supplement M02-A10. CLSI, Wayne, PA, USA, 2009.

28. Chia JH, Chu C, Su LH, Chiu CH, Kuo AJ, Sun CF, et al. (2005) Development of a multiplex PCR and SHV melting-curve mutation detection system for detection of some SHV and CTX-M beta-lactamases of Escherichia coli, Klebsiella pneumonia, and Enterobacter cloacae in Taiwan. J Clin Microbiol 43:4486-4491. PMID: 16145096

29. Shu JC, Chia JH, Kuo AJ, Su LH, Wu TL (2010) A 7-year surveillance for ESBL-producing Escherichia coli and Klebsiella pneumoniae at a university hospital in Taiwan: the incidence of CTX-M-15 in the ICU. Epidemiol Infect 138: 253-263. doi: 10.1017/S0950268809990409 PMID: 19619387

30. Magiorakos AP, Srinivasan A, Carey RB, Carmeli Y, Falagas ME, Giske CG, et al. (2012) Multidrugresistant, extensively drug-resistant and pandrug-resistant bacteria: an international expert proposal for interim standard definitions for acquired resistance. Clin Microbiol Infect 18:268-281. doi: 10.1111/j. 1469-0691.2011.03570.x PMID: 21793988

31. Harris AD, Karchmer TB, Carmeli Y, Samore MH (2001) Methodological principles of case-control studies that analyzed risk factors for antibiotic resistance: a systemic review. Clin Infect Dis 32:1055-1061. PMID: 11264034

32. D'Agata EM (2005) Methodologic issues of case-control studies: a review of established and newly recognized limitations. Infect Control Hosp Epidemiol 26:338-341. PMID: 15865267

33. Thatrimontrichai $A, A$ pisarnthanarak $A$, Chanvitan $P$, Janjindamai $W$, Dissaneevate $S$, Maneenil $G$ (2013) Risk factors and outcomes of carbapenem-resistant Acinetobacter baumannii bacteremia in neonatal intensive car unit: a case-case-control study. Pediatr Infect Dis J 32:140-145. doi: 10.1097/ INF.0b013e318270b108 PMID: 22935872

34. Rodríguez-Baño J, Navarro MD, Romero L, Muniain MA, Cueto Md, Gálvez J, et al. (2008) Risk-factors for emerging bloodstream infections caused by extended-spectrum $\beta$-lactamase-producing Escherichia coli. Clin Microbiol Infect 14:180-183. PMID: 18005358

35. Clark RH, Bloom BT, Spitzer AR, Gerstmann DR (2006) Empiric use of ampicillin and cefotaxime, compared with ampicillin and gentamicin, for neonates at risk for sepsis is associated with an increased risk of neonatal death. Pediatrics 117:67-74. PMID: 16396862

36. Kritsotakis El, Tsioutis C, Roumbelaki M, Christidou A, Gikas A (2011) Antibiotic use and the risk of carbapenem-resistant extended-spectrum- $\beta$-lactamase-producing Klebsiella pneumoniae infection in 
hospitalized patients: results of a double case-control study. J Antimicrob Chemother 66:1383-1391. doi: 10.1093/jac/dkr116 PMID: 21454344

37. Kaier K, Frank U, Hagist C, Conrad A, Meyer E (2009) The impact of antimicrobial drug consumption and alcohol-based hand rub use on the emergence and spread of extended-spectrum beta-lactamaseproducing strains: a time-series analysis. J Antimicrob Chemother 63:609-614. doi: 10.1093/jac/ dkn534 PMID: 19151036

38. Shorr AF (2009) Review of studies of the impact on Gram-negative bacterial resistance on outcomes in the intensive care unit. Crit Care Med 27:1463-1469.

39. Schwaber MJ, Carmeli Y (2007) Mortality and delay in effective therapy associated with extendedspectrum beta-lactamase production in Enterobacteriaceae bactereaemia: a systemic review and meta-analysis. J Antimicrob Chemother 60:913-920. PMID: 17848376

40. Helldal L, Karami N, Florén K, Welinder-Olsson C, Moore ER, Ahrén C (2013) Shift of CTX-M genotypes has determined the increased prevalence of extended-spectrum $\beta$-lactamase-producing Escherichia coli in south-western Sweden. Clin Microbiol Infect 19:E87-E90. doi: 10.1111/1469-0691.12086 PMID: 23190133

41. Khanna N, Boyes J, Lansdell PM, Hamouda A, Amyes SG (2012) Molecular epidemiology and antimicrobial resistance pattern of extended-spectrum- $\beta$-lactamase-producing Enterobacteriaceae in Glasgow, Scotland. J Antimicrob Chemother 67:573-577. doi: 10.1093/jac/dkr523 PMID: 22169188

42. Gibold L, Robin F, Tan RN, Delmas J, Bonnet R (2014) Four-year epidemiological study of extendedspectrum $\beta$-lactamase-producing Enterobacteriaceae in a French teaching hospital. Clin Microbiol Infect 20:20-26.

43. Huang YC, Lien R, Su LH, Chou YH, Lin TY (2011) Successful control of methicillin-resistant Staphylococcus aureus in endemic neonatal intensive care unit-a 7-year campaign. PLOS ONE 6:e23001. doi: 10.1371/journal.pone.0023001 PMID: 21857979

44. Rossolini GM, D'Andrea MM, Mugnaioli C (2008) The spread of CTX-M-type extended-spectrum $\beta$-lactamases. Clin Microbiol Infect 14(suppl I): 33-41.

45. Qureshi ZA, Paterson DL, Peleg AY, Adams-Haduch JM, Shutt KA, Pakstis DL, et al. (2012) Clinical characteristics of bacteremia caused by extended-spectrum $\beta$-lactamase-producing Enterobacteriaceae in the era of CTX-M-type and KPC-type $\beta$-lactamases. Clin Microbiol Infect 18:887-893. doi: 10. 1111/j.1469-0691.2011.03658.x PMID: 21951551 